
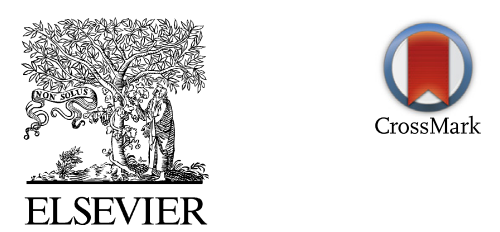

\title{
Bacterial biofilms in the vagina
}

\author{
Liselotte Hardy $^{\mathrm{a}, \mathrm{b}, \mathrm{c}, *}$, Nuno Cerca ${ }^{\mathrm{d}}$, Vicky Jespers ${ }^{\mathrm{a}}$, Mario Vaneechoutte ${ }^{\mathrm{b}}$, Tania Crucitti ${ }^{\mathrm{c}}$ \\ ${ }^{a}$ HIV and Sexual Health Unit, Department of Public Health, Institute of Tropical Medicine, Nationalestraat 155, Antwerp, Belgium \\ ${ }^{\mathrm{b}}$ Laboratory Bacteriology Research, Faculty of Medicine \& Health Sciences, University of Ghent, De Pintelaan 185, Ghent, Belgium \\ ${ }^{c}$ STI Reference Laboratory, Department of Clinical Sciences, Institute of Tropical Medicine, Nationalestraat 155, Antwerp, Belgium \\ ${ }^{\mathrm{d}}$ Laboratory of Research in Biofilms Rosário Oliveira, Centre of Biological Engineering, University of Minho, Rua da Universidade, 4704-553 Braga, Portugal
}

Received 6 November 2016; accepted 13 February 2017

Available online 21 February 2017

\begin{abstract}
A bacterial biofilm is a structured community of bacteria in a self-produced extracellular matrix, adherent to an inert surface or biological tissue. The involvement of biofilm in a bacterial infection implies that the infection is difficult to treat and that the patient will probably experience relapses of the condition. In bacterial vaginosis (BV), the lactobacilli concentration decreases, while the bacterial load of other (facultative) anaerobic bacteria increases. A hallmark of BV is the presence of clue cells, now known as the result of a polymicrobial biofilm formed in vaginal epithelial cells. Current knowledge of the individual roles of bacterial species involved in polymicrobial BV biofilms or interactions between these species are not fully known. In addition, knowledge of the composition matrix and triggers of biofilm formation is still lacking. Bacteria are able to attach to the surface of indwelling medical devices and cover these surfaces with biofilm. Vaginally inserted devices, such as tampons, intra-uterine devices and vaginal rings, can also be colonized by bacteria and be subjected to biofilm formation. This might hamper release of active product in case of drug-releasing devices such as vaginal rings, or promote the presence of unfavorable bacteria in the vagina. This paper reviews current knowledge of biofilms in the vaginal environment.
\end{abstract}

(C) 2017 Institut Pasteur. Published by Elsevier Masson SAS. All rights reserved.

Keywords: Biofilm; Bacterial vaginosis; Contraceptive ring; Gardnerella vaginalis

\section{Bacterial biofilm: introduction}

A bacterial biofilm is a structured community of bacteria that is adherent to an inert surface or biological tissue. The biofilm is enclosed in a mucous substance: a self-produced matrix of extracellular polymeric substances (EPS) [1]. This community is often characterized by a complex internal architecture and contains channels allowing circulation of nutrients [2]. Separate areas in the biofilm can contain genetically identical cells that exhibit different patterns of

\footnotetext{
* Corresponding author. STI Reference Laboratory, Department of Clinical Sciences, Institute of Tropical Medicine, Nationalestraat 155, Antwerp, Belgium.

E-mail addresses: liselotte.hardy@gmail.com (L. Hardy), nunocerca@ceb. uminho.pt (N. Cerca), vjespers@itg.be (V. Jespers), mario.vaneechoutte@ ugent.be (M. Vaneechoutte), tcrucitti@itg.be (T. Crucitti).
}

gene expression [3]. This results in an enhanced tolerance to adverse conditions and better persistence in hostile environments. It offers protection against chemical disinfection, antimicrobial treatment and human immune responses [1].

\subsection{Bacterial biofilm infections}

Biofilm infections share clinical characteristics, regardless of in site in the human body where the biofilm develops. Biofilms grow slowly and symptoms usually appear gradually [4]. Biofilm communities are rarely fully eradicated by the host defense mechanisms. Sessile bacterial biofilm cells release antigens resulting in increased antibody production. However, due to the biofilm structure, the produced antibodies are not capable of killing the biofilm bacteria and accumulate in the surrounding tissues. This can result in immunecomplex-related damage to the same tissues [5]. The biofilm 
also attracts neutrophils that continuously release antimicrobial granule contents and reactive oxygen species that promote collagen degradation and subsequent host tissue injury [6]. On top of that, as antibiotic therapy fails to eradicate all bacteria in the biofilm, only the symptoms caused by the dispersed biofilm bacteria are reversed after treatment [1]. As a result, even after multiple cycles of antibiotic therapy, biofilm infections are characterized by relapses of the condition [3]. In summary, bacterial biofilm causes persistent, slowlyprogressing and chronic infections.

\subsection{Stages in the biofilm life cycle}

Biofilm formation is facilitated by a regulated switch between the planktonic lifestyle of single (motile) cells and the multicellular aggregated sedentary state of bacteria. The biofilm life cycle includes: attachment to a substrate, production of EPS, development of a mature biofilm structure and dispersal by detachment of aggregates or by release of single dispersed cells (Fig. 1).
After first colonization of a surface, bacteria organize into complex multicellular clusters or microcolonies (5-200 $\mu \mathrm{m}$ wide) [7]. They produce EPS, which forms a matrix wherein bacteria are held together and which allows them to develop a three-dimensional structure [7]. This biofilm grows slowly through a combination of cell division and recruitment of other bacteria. Bacterial cells in the biofilm can remain dormant or inactive until the circumstances are favorable for them to start growing, and this results in clinical infections [8]. Within biofilms, gradients of $\mathrm{pH}$, nutrients and oxygen can be found. For example, due to the consumption of oxygen by aerobic biofilm-associated bacteria, an oxygen gradient develops with increasing anaerobic conditions towards the inner stratum or core [7].

When the biofilm increases, the inner cells become separated from the bulk liquid interface at the outside of the biofilm, where most essential sources of energy and nutrients are stored. In addition, waste products and toxins accumulate in the growing biofilm, which can be detrimental to cell survival. Biofilm cells can escape the sessile growth mode for self-

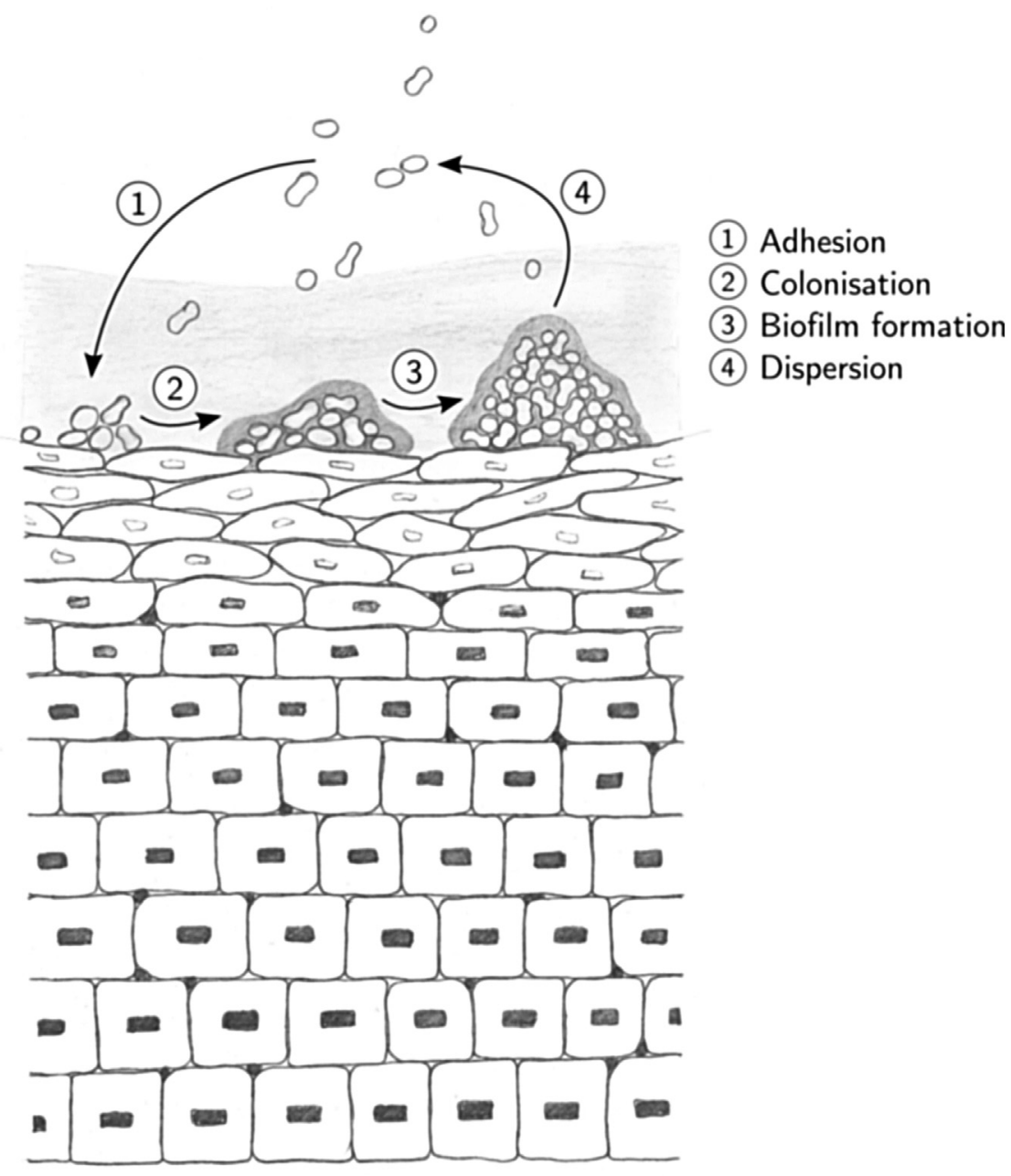

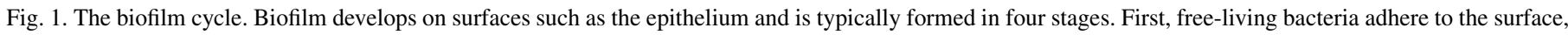

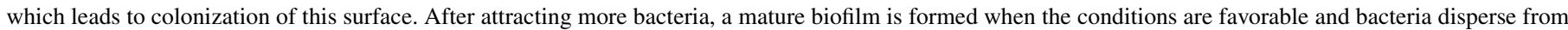
this biofilm to return to the free-living state or to start over on another surface. 
preservation and disseminate to new locations to establish new infections. They may detach from the biofilm structure individually or disperse in aggregates while retaining the biofilm organization [9].

\subsection{The biofilm matrix}

The biofilm matrix determines the immediate living conditions of the bacteria by affecting porosity, density, water content, charge, sorption properties, hydrophobicity and mechanical stability [10]. The composition of the biofilm matrix is highly variable, not only between different species, but also between different strains, and is highly dependent on surrounding environmental conditions [11]. Exopolysaccharides are an important part of the extracellular matrix that additionally comprises a range of biopolymers such as proteins, glycoproteins, glycolipids and extracellular DNA [12].

\subsection{Increased antibiotic resistance and tolerance of biofilm cells}

Biofilms are characterized by decreased susceptibility to antimicrobial agents. Next to the known mechanisms of bacterial resistance [13], treatment of biofilm-related illness is challenging due the specific architecture of this biofilm. First of all, the applied antibiotics can be pumped out of the biofilm or can be degraded by the active bacteria in the outer biofilm subpopulation [14]. Furthermore, the biofilm matrix forms a barrier against all antibiotics, even though this is not completely impermeable (as demonstrated by mathematical models [15] and experimentally for some antibiotics [16]). Relatively large antibiotic compounds may be constrained by the viscous matrix and be slowed down, resulting in decreased penetration in the biofilm [17]. The matrix components can also chemically neutralize antimicrobial compounds [18]. Other biofilmenvironment-related factors, such as differences in $\mathrm{pH}, \mathrm{pCO}_{2}$ or $\mathrm{pO}_{2}$, may further affect the efficacy of the antimicrobials $[19,20]$. Due to the existence of several bacteria layers in the biofilm, nutrients and oxygen are depleted in the biofilm core. This nutrition and oxygen gradient slows down the growth and metabolism of bacteria in the inner stratum of the biofilm [21-23]. The subpopulation of bacteria residing in the biofilm core is a group of dormant bacteria, and their presence can be influenced by the biofilm growth conditions [24,25]. When exposed to antibiotics, some of the dormant bacteria acquire increased tolerance towards antibiotics without undergoing genetic changes, and are known as 'persisters' [26]. In 1942, Hobby et al. [27] discovered that 1\% of Staphylococcus aureus cells were not killed by penicillin. As such, persister cells can lead to relapses after treatment: when the concentration of antibiotic compounds drops, the persister cells revert to their phenotype, causing re-growth of the biofilm [28].

\subsection{Communication between bacteria}

Communication between neighboring bacterial cells occurs through quorum sensing. It allows bacteria to monitor the environment for other bacteria and alter their behavior in response to changes in the number of cells (quorum) and/or species present in the community. The communication process requires the production and constitutive release of small hormone-like chemical signaling molecules called autoinducers. The concentration of released auto-inducers increases as a function of cell density. Above a certain threshold, it will trigger an alteration in the expression profile of the individual cells [29]. Consequently, bacterial biofilms can act as multicellular organisms with different gene expression patterns among genetically identical cells [30].

Due to the spatial heterogeneity and biodiversity in mixedspecies biofilms, the "calling distance" can be an important factor in quorum sensing. Egland et al. [31] demonstrated that signaling occurred mainly within cell clusters, rather than across them. Therefore, it is suggested that the distance between bacteria may be more important than the number of cells present. Thus, auto-inducer accumulation may be dependent not only on population density, but also on cell proximity [32].

\subsection{Multispecies biofilms}

Most bacteria live within a multispecies biofilm, interacting with cells of the other species. These interspecific interactions can be antagonistic or synergistic, and include communication via quorum sensing. Synergistic interactions results in the optimization of living conditions in biofilms, for example, through metabolic collaboration between bacteria where one species utilizes a metabolite that was produced by a neighboring species [33], or through the establishment of an oxygen gradient allowing anaerobic bacteria to survive in the biofilm $[7,34,35]$. An example of a multispecies vaginal biofilm is the biofilm involved in bacterial vaginosis (BV) [36], which is discussed in the next section.

\section{Biofilm associated with bacterial vaginosis}

\subsection{Bacterial vaginosis}

A healthy vaginal microbiome can be defined as a vaginal environment in which infections or symptoms are absent and that is associated with good reproductive health outcome [37]. Furthermore, the healthy vaginal microbiome is typically dominated by a limited number of different Lactobacillus species (Fig. 2), whereas BV is a polybacterial dysbiosis (Fig. 3). The lactobacilli concentration (with the exception of Lactobacillus iners) decreases during BV, while the bacterial load of other (facultative) anaerobic bacteria, such as Gardnerella vaginalis, Atopobium vaginae, Prevotella spp., Sneathia spp. and many others increases [38,39].

\subsection{Biofilm in bacterial vaginosis}

The ability of $G$. vaginalis, probably the most prevalent and abundant species in $\mathrm{BV}$, to colonize human cells was already established in the eighties $[40,41]$. In fact, the presence of 

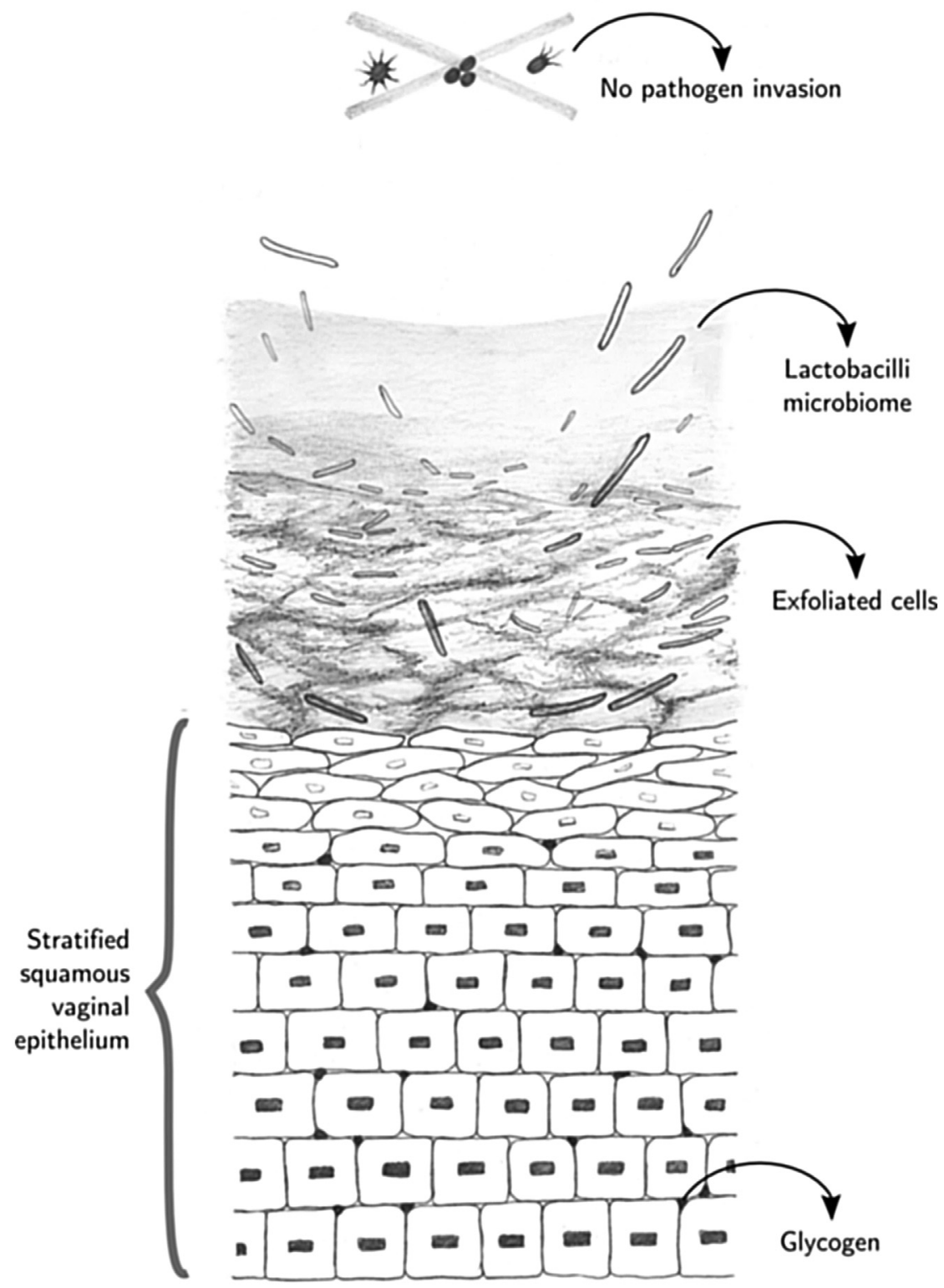

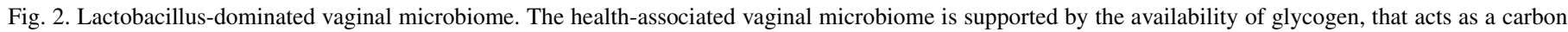

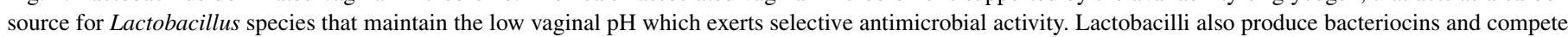
for receptor sites on the vaginal epithelium with non-advantageous and pathogenic species.

epithelial cells covered with bacteria, or clue cells (meaning: characteristic cells that provide a clue to recognizing $\mathrm{BV}$ ), is one of the Amsel criteria used in clinical settings to diagnose the condition. Such coating of epithelial cells with multiple layers of bacteria is exactly what one expects to see in case of biofilm formation. In reality, we have been looking at clue cells for decades, without realizing that we were dealing with biofilm formation. However, it was not until 2005 that Swidsinski and colleagues [36] demonstrated the presence of this polymicrobial biofilm adhering to the vaginal epithelial cells in $\mathrm{BV}$, using fluorescence in situ hybridization (FISH). After this first demonstration, other groups developed probes for other associated bacteria to visualize microorganisms involved in BV [42-44].
Providing further evidence for the biofilm nature of BV, the treatment of $\mathrm{BV}$ is very challenging due to recurrence and relapses after antibiotic therapy, as is also the case in other biofilm-associated infections. Little is known about the exact mechanisms of biofilm formation in $\mathrm{BV}$ : the genes responsible, communication strategies (quorum sensing, metabolic communication) and genetic exchanges between biofilmassociated bacteria. Although it has been established that BV is a polymicrobial condition that involves a polymicrobial biofilm, we do not know the importance of the separate members nor the mechanisms of how these species interact. As such, it is not clear whether all species found in the BV biofilm have a role in pathogenesis, or are simply a consequence of biofilm formation on the vaginal epithelium [45]. 


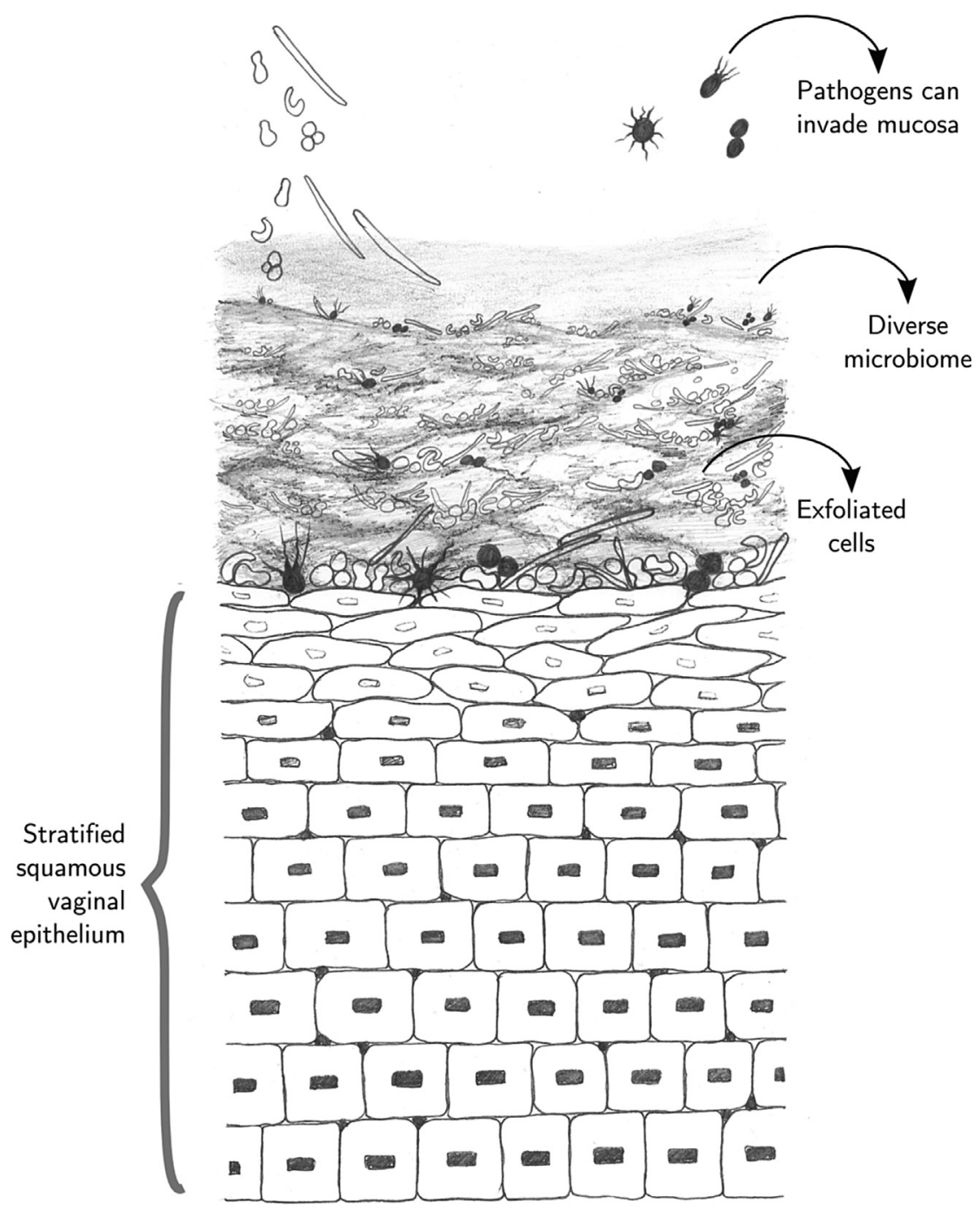

Fig. 3. Bacterial vaginosis-associated vaginal microbiome. In the dysbiosis-associated vaginal microbiome, beneficial lactobacilli are outnumbered by other microaerophilic and anaerobic organisms. This is accompanied by a degradation of the mucus layer and disruption of the barrier function that results in increased exposure to non-advantageous and pathogenic species and viral pathogens.

Limited in vitro data reveal synergistic interactions between $G$. vaginalis and other BV-associated bacteria [46]. G. vaginalis is thought to be an important player in $\mathrm{BV}$, even though it also occurs in the healthy vaginal microbiome [47]. However, genomic and microbiological data suggest the existence of multiple lineages of $G$. vaginalis, among which presumably not all strains will be able to cause BV [48-52].

The presence of $G$. vaginalis in vaginal eubiosis as well as in vaginal dysbiosis might be the result of a mere quantitative difference, with many more cells of this species present in dysbiosis [38], but qualitative differences might be evoked as well. A possible explanation for this phenomenon may be related to a lower capacity of initial adhesion to the vaginal epithelium of a specific subset of G. vaginalis strains [53]. G. vaginalis has multiple virulence factors that may contribute to development of a biofilm. Specifically, the presence of fimbriae [54] and the ability to produce sialidase [52,55-57], and vaginolysin [58] could play a major role in the colonization of the vaginal epithelial cells, and its ability to produce EPS [54] could be important in the maturation of the biofilm.

It is therefore tempting to consider $G$. vaginalis as the initial colonizer that provides a scaffold to which other bacteria, secondary colonizers, attach in order to establish a mature biofilm. One of these secondary colonizers is $A$. vaginae [59], an obligate anaerobic species, that has been linked to BV $[60,61]$, and that, unlike G. vaginalis, is usually not present in the health-related vaginal microbiome. The detection of a vaginal biofilm with both G. vaginalis and $A$. vaginae (Fig. 4) is associated with a higher probability of having BV, as assessed by the Nugent criteria [59].

\subsection{Treatment of bacterial vaginosis}

Currently available antibiotics used for oral or vaginal treatment of BV (metronidazole, tinidazole and clindamycin) have poor initial cure rates and high relapse rates in those who 


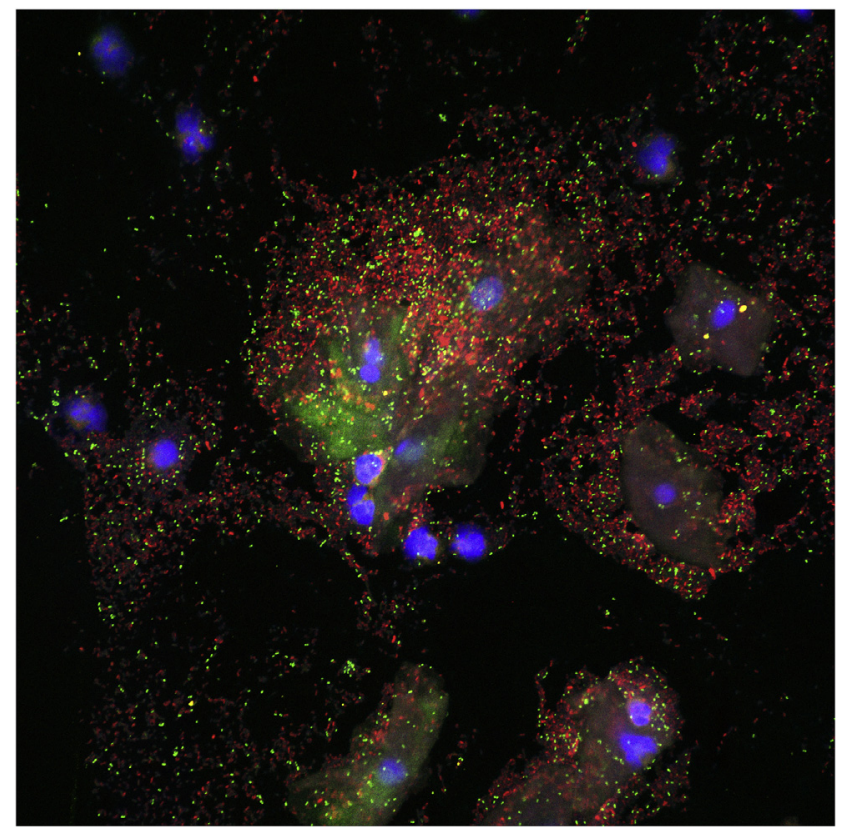

Fig. 4. Superimposed fluorescence in situ hybridization image of polymicrobial biofilm of Atopobium vaginae and Gardnerella vaginalis. Montage of confocal laser scanning microscopy images with $400 \times$ magnification of polymicrobial biofilm in a vaginal sample: vaginal epithelial cells DAPI in blue, G. vaginalis specific PNA-probe Gard162 with Alexa Fluor 647 in red and A. vaginae specific PNA-probe AtoITM1 with Alexa Fluor 488 in green. (For interpretation of the references to colour in this figure legend, the reader is referred to the web version of this article.)

showed an initial response [62,63]. In addition, antibiotic treatment could possibly result in drug resistance in $\mathrm{BV}$ associated bacteria such as $G$. vaginalis, A. vaginae, Prevotella spp., Bacteroides spp. and Peptostreptococcus spp. [64-67]. Alternatives for these ineffective antibiotic treatments are increasingly being explored: antiseptics, disinfectants, vaginal acidifying and buffering agents, combination therapies, and vaginal and oral probiotics, but until now, none has been found to be successful $[68,69]$.

One possible approach to dealing with $\mathrm{BV}$ is the restoration of the vaginal environment by the administration of live microorganisms, or probiotics [62,70-72], while other approaches try to tackle the biofilm. Strategies to destroy the biofilm and treat BV could involve acidifying the vaginal environment [73], application of synthetic antimicrobial peptides [74], application of antiseptics [75] and plant-derived compounds [76] and destruction of the biofilm matrix [77]. Combination therapies that combine disruption of the biofilm matrix with specific bactericidal effects will likely be most effective. For example, recent in vitro work by Gottschick et al. [78] demonstrated that attacking the biofilm and the bacterial cells by a combination of an amphoteric tenside sodium coco-amphoacetate and the antibiotic metronidazole might be a useful strategy against BV. While the antibiotics metronidazole and tobramycin were highly effective in preventing biofilm formation, they could not destroy the established biofilm, but co-administration of amphoteric tenside increased the effect of metronidazole on reducing the biomass by $40 \%$ and on viability by $61 \%$.
An approach that is still understudied is the use of bacteriophages in the treatment of $\mathrm{BV}$, although a number of studies using phages in other biofilm-associated infections have already been carried out [79]. Phage therapy could provide a natural, highly specific and safe approach controlling BVassociated bacteria if the phages are able to reach the biofilm in sufficient concentrations [80,81]. Controlled infection with a mixture of bacteriophages would result in the lysis and killing of specific targeted bacteria. The active penetration of phages in the biofilm has an impact on the structure of biofilms and promotes the release of new phage virions that will infect adjacent bacteria $[80,81]$. Additionally, certain bacteriophages can express EPS depolymerase enzymes [82,83] that contribute to the degradation of the biofilm matrix and structure. However, currently, no bacteriophages for BV-associated bacteria have been described, and the interactions of natural bacteriophages with the matrix of the BV biofilm will also need to be studied more extensively before this approach can be taken into consideration.

And finally, another understudied approach to eradicating BV biofilm would be an interaction with quorum sensing, or cell-cell communication. The potential of small chemical compounds to interfere with the communication between bacterial cells is being investigated $[79,84]$. However, there is still little or no knowledge available on quorum sensing in BV biofilm, let alone on how to interfere with it.

\section{Bacterial biofilm on vaginal devices}

Microorganisms are able to attach to the surface of indwelling medical devices and cover these surfaces with biofilm. For example, the most important reason to surgically remove implanted prostheses is the development of biofilm and associated infections at the implantation site $[85,86]$. Bacteria might also be able to attach to vaginally inserted devices, but as yet, little information is available regarding this topic.

\subsection{Bacterial biofilm on tampons}

The only study thus far looking into biofilm development on tampon fibers focussed on S. aureus biofilm [87]. S. aureus can cause a menstrual toxic shock syndrome through production of toxin shock syndrome toxin (TSST-1). However, only $10-20 \%$ of the $S$. aureus colonizing the vaginal tract produce this toxin. It has been reported that the rate of colonization is higher during menses [88]. The study used molecular amplification techniques to confirm the presence of $S$. aureus in vaginal specimens and FISH to observe biofilm on tampons and in vaginal wash specimens. Cell-adherent bacterial biofilm was observed in the vaginal wash specimens and on tampon fibers from healthy menstruating women.

\subsection{Bacterial biofilm on intra-uterine devices}

Evidence for biofilm formation on copper intra-uterine devices (IUDs) has been demonstrated in a number of 

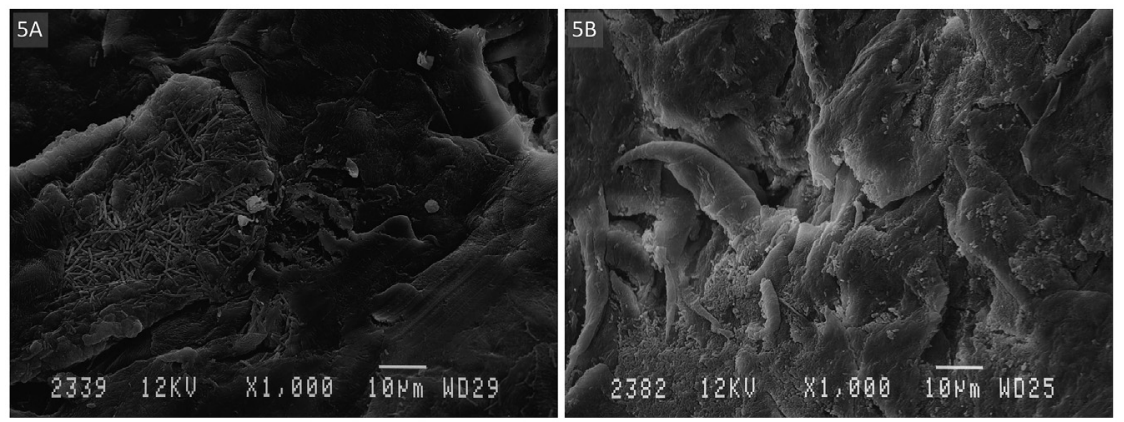

Fig. 5. Visualization of biomass on an intravaginal ring surface by scanning electron microscopy at $1000 \times$ magnification: A) phenotype 1: elongated bacteria scattered on vaginal epithelial cells; B) phenotype 2: condensed biofilm of bacilli on vaginal epithelial cells.

publications. Lactobacilli, streptococci, Corynebacterium spp. and Micrococcus spp. have been isolated from removed IUDs $[89,90]$. Shanmughapriya et al. confirmed previous observations of Actinomycetes spp. proliferating in the endocervix of IUD users [91]. They showed in vitro that Nocardia spp. were able to form biofilm on copper sheets. Also, Actinomyces israelii was able to colonize copper IUDs [92]. Elsayed et al. reported a case of IUD-associated pelvic actinomycosis due to Actinomyces urogenitalis in a previously healthy young adult woman [93]. A mixture of anaerobic bacteria was cultured from a copper IUD removed after 10 years of use from a woman presenting symptoms of pelvic inflammatory disease. The scanning electron microscopy (SEM) picture of the IUD showed a mature bacterial biofilm involving coccal and bacillary forms on the IUD's surface [94].

\subsection{Bacterial biofilm on intravaginal rings}

Intravaginal rings delivering hormones are being used in the context of pregnancy prevention or estrogen replacement therapy. However, few studies have investigated biofilm formation on intravaginal rings in humans. Miller et al. [95] examined a contraceptive vaginal ring (CVR), NuvaRing, after four weeks of use by one healthy volunteer, and observed only cellular debris, but no bacterial growth on the surface of the ring using scanning electron microscopy, although this may be due to a technical shortcoming, as they visualized the ring surface only at very low magnification. A study in human volunteers showed the presence of biomass on all 48 rings containing an antiretroviral drug that were used for four weeks [96]. In this population of women, among whom more than two-thirds had a normal Nugent score, the ring biomass density (semi-quantified visually with SEM) was not associated with the diagnosis of $\mathrm{BV}$, according to Nugent [96].

A recent study among Rwandan women using the NuvaRing ${ }^{\circledR}$ [97] clearly demonstrated the accumulation of biomass consisting of vaginal epithelial cells and associated bacteria, on intravaginal rings inserted for three weeks. The higher the Nugent score in the women using the NuvaRing ${ }^{\circledR}$, the higher the biomass density, measured by crystal violet staining. Furthermore, the density of the biomass was associated with the presence of a vaginal biofilm visualized using FISH with peptide nucleic acid (PNA) probes specifically targeting G. vaginalis and A. vaginae [97]. Lactobacilli were also identified in the CVR biomass, but neither their presence nor their concentration was correlated with the biomass density. Overall, the biomass consisted of vaginal epithelial cells with bacterial species in the same ratio as those found in the vaginal secretions of the women. Consequently, it was concluded that the biomass on the vaginal rings mirrored the vaginal microbiome of the women. SEM pictures of the CVRs used showed two types of biomass structure. Fig. 5a shows an accumulation of vaginal epithelial cells covered by a loose structure of scattered elongated bacteria with a morphology compatible with lactobacilli (type 1), whereas Fig. 5b demonstrates vaginal epithelial cells coated by a dense structure of coccobacillar bacteria, compatible with a biofilm structure (type 2). The presence of type 2 biomass coincided with a vaginal BV Nugent score above 7 and the presence of a vaginal biofilm and of $\mathrm{BV}$-associated bacteria present in the vagina according to $\mathrm{qPCR}$ [97].

Other bacteria that are occasionally found in the vaginal environment, such as the pathogen Neisseria gonorrhoeae, have been shown in vitro to form biofilm on intravaginal rings [98]. The ability of the gonococci to form biofilm was greater on intravaginal rings that included silicone as compared to thermoplastic ring material [98].

Only a limited number of studies on the formation of biomass on intravaginal rings have been carried out. More research still needs to be done on the impact of biomass and biofilm on the vaginal microbiota and on the product release properties of the vaginal delivery device.

\section{Conclusions}

Biofilm formed on vaginal epithelial cells is an important process in the pathogenesis of bacterial vaginosis. Multispecies biofilms associated with bacterial vaginosis have been visualized. Knowledge of the composition of the in vivo extracelullar matrix and triggers of biofilm formation such as quorum sensing is still lacking. Research aimed at characterizing BV-associated biofilm is required. This knowledge will lead to the design of adequate treatments of $\mathrm{BV}$ that would prevent recurrence of the condition. Additionally, more research is needed regarding the formation of biofilm or biomass on vaginally inserted devices, such as vaginal rings used for therapeutic or preventive 
purposes. Intravaginal rings are being investigated as delivery systems for products for BV prevention, for example, by the addition of lactic acid or for hormones, combined with antimicrobial products, including antiretroviral drugs. The deposit of biomass or formation of biofilm on these rings might hamper the release of the active product or promote the presence of unfavorable bacteria in the vagina, and should thus be considered when developing these products.

\section{Conflict of interest}

The authors declare no conflict of interest.

\section{References}

[1] Costerton JW, Stewart PS, Greenberg EP. Bacterial biofilms: a common cause of persistent infections. Science 1999;284:1318-23.

[2] de Beer D, Stoodley P, Lewandowski Z. Liquid flow in heterogeneous biofilms. Biotechnol Bioeng Aug. 1994;44(5):636-41.

[3] Costerton JW, Lewandowski Z, Caldwell DE, Korber DR, LappinScott HM. Microbial biofilms. Annu Rev Microbiol 1995;49(1):711-45.

[4] Ward KH, Olson ME, Lam K, Costerton JW. Mechanism of persistent infection associated with peritoneal implants. J Med Microbiol 1992;36: 406-13.

[5] Cochrane DMG, Brown MRW, Anwar H, Weller PH, Lam K, Costerton JW. Antibody response to Pseudomonas aeruginosa surface protein antigens in a rat model of chronic lung infection. J Med Microbiol 1988;27:255-61.

[6] Hirschfeld J. Dynamic interactions of neutrophils and biofilms. J Oral Microbiol 2014;6 [no. 26102].

[7] Stacy A, Mcnally L, Darch SE, Brown SP, Whiteley M. The biogeography of polymicrobial infection. Nat Rev Microbiol 2016;14:93-105.

[8] Wood TK, Knabel SJ, Kwan W. Bacterial persister cell formation and dormancy. Appl Environ Microbiol 2013;79(23):7116-21.

[9] Stoodley P, Sauer K, Davies DG, Costerton JW. Biofilms as complex differentiated communities. Annu Rev Microbiol 2002;56:187-209.

[10] Flemming H-C, Wingender J. Extracellular polymeric substances: structure, ecological functions, technical relevance. In: Bitton G, editor. Encyclopedia of environmental microbiology, vol. 3. New York, NY: Wiley; 2002. p. 1223-31.

[11] Flemming H-C, Wingender J. The biofilm matrix. Nat Rev Microbiol 2010;8(9):623-33.

[12] Flemming HC, Neu TR, Wozniak DJ. The EPS matrix: the 'house of biofilm cells'. J Bacteriol 2007;189(22):7945-7.

[13] Walsh C. Molecular mechanisms that confer antibacterial drug resistance. Nature 2000;406:775-81.

[14] Van Acker H, Van Dijck P, Coenye T. Molecular mechanisms of antimicrobial tolerance and resistance in bacterial and fungal biofilms. Trends Microbiol 2014;22(6):326-33.

[15] Stewart PS. A review of experimental measurements of effective diffusive permeabilities and effective diffusion coefficients in biofilms. Biotechnol Bioeng Aug. 1998;59(3):261-72.

[16] Jefferson KK, Goldmann DA, Pier GB. Use of confocal microscopy to analyze the rate of vancomycin penetration through Staphylococcus aureus biofilms. Antimicrob Agents Chemother 2005;49(6):2467-73.

[17] Cerca N, Martins S, Cerca F, Jefferson KK, Pier GB, Azeredo J. Comparative assessment of antibiotic susceptibility of coagulasenegative staphylococci in biofilm versus planktonic culture as assessed by bacterial enumeration or rapid XTT colorimetry. J Antimicrob Chemother 2006;56(2):331-6.

[18] Fux CA, Costerton JW, Stewart PS, Stoodley P. Survival strategies of infectious biofilms. Trends Microbiol 2005;13(1):34-40.

[19] Teitzel GM, Parsek MR. Heavy metal resistance of biofilm and planktonic Pseudomonas aeruginosa. Appl Environ Microbiol Apr. 2003; 69(4):2313-20.
[20] Walters MC, Roe F, Bugnicourt A, Franklin MJ, Stewart PS. Contributions of antibiotic penetration, oxygen limitation and low metabolic activity to tolerance of Pseudomonas aeruginosa biofilms to ciprofloxacin and tobramycin. Antimicrob Agents Chemother Jan. 2003;47(1):317-23.

[21] Bhargava P, Collins JJ. Boosting bacterial metabolism to combat antibiotic resistance. Cell Metab 2015;21(2):154-5.

[22] Urish KL, DeMuth PW, Kwan BW, Craft DW, Ma D, Haider H, et al Antibiotic-tolerant Staphylococcus aureus biofilm persists on arthroplasty materials. Clin Orthop Relat Res 2016;474(7):1649-56.

[23] Yang S, Hay ID, Cameron DR, Speir M, Cui B, Su F, et al. Antibiotic regimen based on population analysis of residing persister cells eradicates Staphylococcus epidermidis biofilms. Nat Sci Rep 2015;5:1-11 [no. 18578].

[24] Carvalhais V, França A, Cerca F, Vitorino R, Pier GB, Vilanova M, et al. Dormancy within Staphylococcus epidermidis biofilms: a transcriptomic analysis by RNA-seq. Appl Microbiol Biotechnol 2014;98(6):2585-96.

[25] Cerca Filipe, Trigo Gabriela, Correia Alexandra, Cerca Nuno, Azeredo Joana, Vilanova Manuel. SYBR green as a fluorescent probe to evaluate the biofilm physiological state of Staphylococcus epidermidis, using flow cytometry. Can J Microbiol 2011;57(10):850-6.

[26] Prax M, Bertram R. Metabolic aspects of bacterial persisters. Front Cell Infect Microbiol 2014;4(October):1-6.

[27] Hobby L, Meyer K, Chaffee E. Observations on the mechanism of action of penicillin. Proc Soc Exp Biol Med 1942;50:281-5.

[28] Lewis K. Persister cells. Annu Rev Microbiol 2010;64:357-72.

[29] Ng W-L, Bassler BL. Bacterial quorum-sensing network architectures. Annu Rev Genet 2009;43:197-222.

[30] Waters CM, Bassler BL. Quorum sensing: cell-to-cell communication in bacteria. Annu Rev Cell Dev Biol 2005;21:319-46.

[31] Egland PG, Palmer RJ, Kolenbrander PE. Interspecies communication in Streptococcus gordonii-Veillonella atypica biofilms: signaling in flow conditions requires juxtaposition. PNAS 2004;101(48):16917-22.

[32] Hense BA, Kuttler C, Muller J, Rothballer M, Hartmann A, Kreft J-U. Does efficiency sensing unify diffusion and quorum sensing? Nat Rev Microbiol Mar. 2007;5(3):230-9.

[33] Elias S, Banin E. Multispecies biofilms: living with friendly neighbors. FEMS Microbiol Rev 2012;36(5):990-1004.

[34] Bradshaw DJ, Marsh PD, Keith Watson G, Allison C. Role of Fusobacterium nucleatum and coaggregation in anaerobe survival in planktonic and biofilm oral microbial communities during aeration. Infect Immun 1998;66(10):4729-32.

[35] Sbordone RL, Bortolaia C. Oral microbial biofilms and plaque-related diseases: microbial communities and their role in the shift from oral health to disease. Clin Oral Investig 2003; 7:181-8.

[36] Swidsinski A, Mendling W, Loening-Baucke V, Ladhoff A, Swidsinski S, Hale LP, et al. Adherent biofilms in bacterial vaginosis. Obstet Gynecol 2005;106(5 Pt 1):1013-23.

[37] Ma B, Forney L, Ravel J. The vaginal microbiome: rethinking health and diseases. Annu Rev Microbiol 2012;66:371-89.

[38] van de Wijgert JHHM, Borgdorff H, Verhelst R, Crucitti T, Francis S, Verstraelen $\mathrm{H}$, et al. The vaginal microbiota: what have we learned after a decade of molecular characterization? PLoS One 2014;9(8):e105998.

[39] Onderdonk AB, Delaney ML, Fichorova N. The human microbiome during bacterial vaginosis. Clin Microbiol Rev 2016;29(2):223-38.

[40] Scott TG, Curran B, Smyth CJ. Electron microscopy of adhesive interactions between Gardnerella vaginalis and vaginal epithelial cells, McCoy cells and human red blood cells. J Gen Microbiol 1989;135: 475-80.

[41] Johnson AP, Boustouller YL. Extra-vaginal infection caused by Gardnerella vaginalis. Epidemiol Infect 1987;98:131-7.

[42] Machado A, Almeida C, Salgueiro D, Henriques A, Vaneechoutte M, Haesebrouck F, et al. Fluorescence in situ hybridization method using peptide nucleic acid probes for rapid detection of Lactobacillus and Gardnerella spp. BMC Microbiol 2013;13(82).

[43] Fredricks DN. Molecular methods to describe the spectrum and dynamics of the vaginal microbiota. Anaerobe 2011;17(4):191-5.

[44] Hardy L, Jespers V, Dahchour N, Mwambarangwe L, Musengamana V, Vaneechoutte M, et al. Unravelling the bacterial vaginosis-associated 
biofilm: a multiplex Gardnerella vaginalis and Atopobium vaginae fluorescence in situ hybridization assay using peptide nucleic acid probes. PLoS One 2015;10(8):1-16.

[45] Machado A, Cerca N. Influence of biofilm formation by Gardnerella vaginalis and other anaerobes on bacterial vaginosis. J Infect Dis June 16, 2015.

[46] Castro J, Cerca N. BV and non-BV associated Gardnerella vaginalis establish similar synergistic interactions with other BV-associated microorganisms in dual-species biofilms. Anaerobe 2015;36:56-9.

[47] Menard J-P, Fenollar F, Henry M, Bretelle F, Raoult D. Molecular quantification of Gardnerella vaginalis and Atopobium vaginae loads to predict bacterial vaginosis. Clin Infect Dis 2008;47(1):33-43.

[48] Harwich MD, Alves JM, Buck GA, Strauss JF, Patterson JL, Oki AT, et al. Drawing the line between commensal and pathogenic Gardnerella vaginalis through genome analysis and virulence studies. BMC Genomics 2010;11:375.

[49] Schellenberg JJ, Jayaprakash TP, Gamage NW, Patterson MH, Vaneechoutte M, Hill JE. Gardnerella vaginalis subgroups defined by cpn 60 sequencing and sialidase activity in isolates from Canada, Belgium and Kenya. PLoS One 2016;11(1):1-12.

[50] Piot P, van Dyck E, Peeters M, Hale J, Totten PA, Holmes K. Biotypes of Gardnerella vaginalis. J Clin Microbiol 1984;20(4):677-9.

[51] Castro J, Alves P, Sousa C, Cereija T, Franca A, Cerca N. Functional analysis of virulence potential of commensal and clinical Gardnerella vaginalis isolates using an in-vitro biofilm model. Nat Sci Rep 2015: 1-10. November 2014.

[52] Lopes Dos Santos Santiago G, Deschaght P, El Aila N, Kiama TN, Verstraelen H, Jefferson KK, et al. Gardnerella vaginalis comprises three distinct genotypes of which only two produce sialidase. Am J Obstet Gynecol 2011;204(5). 450.e1-e7.

[53] Castro J, Alves P, Sousa C, Cereija T, França A, Jefferson KK, et al. Using an in-vitro biofilm model to assess the virulence potential of bacterial vaginosis or non-bacterial vaginosis Gardnerella vaginalis isolates. Sci Rep Jun 26, 2015;5:11640.

[54] Catlin BW. Gardnerella vaginalis: characteristics, clinical considerations and controversies. Clin Microbiol Rev 1992;5(3):213-37.

[55] Cauci S, Culhane JF, Di Santolo M, McCollum K. Among pregnant women with bacterial vaginosis, the hydrolytic enzymes sialidase and prolidase are positively associated with interleukin-1 $\beta$. Am J Obstet Gynecol 2008;198(1).

[56] Hardy L, Jespers V, Van den Bulck M, Buyze J, Mwambarangwe L, Musengamana V, et al. The presence of the putative Gardnerella vaginalis sialidase A gene in vaginal specimens is associated with bacterial vaginosis biofilm. PLoS One 2017;12(2):e0172522.

[57] Cauci S, McGregor J, Thorsen P, Grove J, Guaschino S. Combination of vaginal $\mathrm{pH}$ with vaginal sialidase and prolidase activities for prediction of low birth weight and preterm birth. Am J Obstet Gynecol 2005;192(2): 489-96.

[58] Pleckaityte M, Janulaitiene M, Lasickiene R, Zvirbliene A. Genetic and biochemical diversity of Gardnerella vaginalis strains isolated from women with bacterial vaginosis. FEMS Immunol Med Microbiol 2012; 65(1):69-77.

[59] Hardy L, Jespers V, Abdellati S, De Baetselier I, Mwambarangwe L, Musengamana V, et al. A fruitful alliance: the synergy between Atopobium vaginae and Gardnerella vaginalis in bacterial vaginosisassociated biofilm. Sex Transm Infect 2016;0:1-5.

[60] Ferris MJ, Masztal A, Aldridge KE, Fortenberry JD, Fidel PL, Martin DH. Association of Atopobium vaginae, a recently described metronidazole resistant anaerobe, with bacterial vaginosis. BMC Infect Dis 2004;4:5.

[61] Verhelst R, Verstraelen H, Claeys G, Verschraegen G, Delanghe J, Van Simaey L, et al. Cloning of 16S rRNA genes amplified from normal and disturbed vaginal microflora suggests a strong association between Atopobium vaginae, Gardnerella vaginalis and bacterial vaginosis. BMC Microbiol 2004;4:16.

[62] Senok AC, Verstraelen H, Temmerman M, Botta GA. Probiotics for the treatment of bacterial vaginosis. Cochrane Database Syst Rev 2009;4.

[63] Oduyebo OO, Anorlu RI, Ongunsola FT. The effects of antimicrobial therapy on bacterial vaginosis in non-pregnant women. Cochrane Database Syst Rev 2009;3(CD006055).
[64] Lubbe MM, Botha LP, Chalkley JL. Comparative activity of eighteen antimicrobial agents against anaerobic bacteria isolated in South Africa. Eur J Clin Microbiol Infect Dis 1999;18(1):46-54.

[65] Bryskier A. Anti-anaerobic activity of antibacterial agents. Expert Opin Investig Drugs 2001;10(2):239-67.

[66] Liebetrau A, Rodloff AC, Dubreuil L. In vitro activities of a new desfluoro (6) quinolone, garenoxacin, against clinical anaerobic bacteria. Antimicrob Agents Chemother 2003;47(11):3667-71.

[67] De Backer E, Verhelst R, Verstraelen H, Claeys G, Verschraegen G, Temmerman M, et al. Antibiotic susceptibility of Atopobium vaginae. BMC Infect Dis 2006;6:51.

[68] Verstraelen H, Verhelst R. Bacterial vaginosis: an update on diagnosis and treatment. Expert Rev Anti Infect Ther 2009;7(9):1109-24.

[69] Bradshaw CS, Sobel JD. Current treatment of bacterial vaginosis limitations and need for innovation. J Infect Dis 2016;214(S1):S14-20.

[70] Machado D, Castro J, Palmeira-de-Oliveira A, Martinez-de-Oliveira J, Cerca N. Bacterial vaginosis biofilms: challenges to current therapies and emerging solutions. Front Microbiol 2016;6(1528).

[71] McMillan A, Dell M, Zellar MP, Cribby S, Martz S, Hong E, et al. Disruption of urogenital biofilms by lactobacilli. Colloids Surf B Biointerf 2011;86(1):58-64.

[72] Saunders S, Bocking A, Challis J, Reid G. Effect of Lactobacillus challenge on Gardnerella vaginalis biofilms. Colloids Surf B Biointerf 2007;55:138-42.

[73] Boskey ER, Cone RA, Whaley KJ, Moench TR. Origins of vaginal acidity: high $\mathrm{D} / \mathrm{L}$ lactate ratio is consistent with bacteria being the primary source. Hum Reprod Sep. 2001;16(9):1809-13.

[74] Hooven TA, Randis TM, Hymes SR, Rampersaud R, Ratner AJ. Retrocyclin inhibits Gardnerella vaginalis biofilm formation and toxin activity. J Antimicrob Chemother 2012;67(12):2870-2.

[75] Verstraelen H, Verhelst R, Roelens K, Temmerman M. Antiseptics and disinfectants for the treatment of bacterial vaginosis: a systematic review. BMC Infect Dis 2012;12(1):148.

[76] Palmeira-de-Oliveira A, Silva BM, Palmeira-de-Oliveira R, Martinez-deOliveira J, Salgueiro L. Are plant extracts a potential therapeutic approach for genital infections? Curr Med Chem 2013;20(23):2914-28.

[77] Xavier JB, Picioreanu C, Rani SA, Van Loosdrecht MCM, Stewart PS. Biofilm-control strategies based on enzymic disruption of the extracellular polymeric substance matrix - a modelling study. Microbiology 2005;151:3817-32.

[78] Gottschick C, Szafranski SP, Kunze B, Sztajer H. Screening of compounds against Gardnerella vaginalis biofilms. PLoS One 2016;11(4): e0154086.

[79] Simões M, Simões LC, Vieira MJ. A review of current and emergent biofilm control strategies. LWT - Food Sci Technol 2010;43(4):573-83.

[80] Abedon ST. Ecology of anti-biofilm agents I: antibiotics versus bacteriophages. Pharmaceuticals 2015;8:525-58.

[81] Abedon ST. Bacteriophage exploitation of bacterial biofilms: phage preference for less mature targets? FEMS Microbiol Lett 2016;363. fnv246.

[82] Hughes KA, Sutherland IW, Clark J, V Jones M. Bacteriophage and associated polysaccharide depolymerases - novel tools for study of bacterial biofilms. J Appl Microbiol 1998;85:583-90.

[83] Hughes KA, Sutherland IW, Jones MV, Rutherford D. Biofilm susceptibility to bacteriophage attack: the role of phage-borne polysaccharide depolymerase. Microbiology 1998;144:3039-47.

[84] Jakobsen TH, Bjarnsholt T, Jensen PØ, Givskov M, Høiby N. Targeting quorum sensing in Pseudomonas aeruginosa biofilms: current and emerging inhibitors. Future Microbiol 2013;8(7):901-21.

[85] Donlan RM. Biofilms and device-associated infections. Emerg Infect Dis 2001;7(2):277-81.

[86] Feng G, Cheng Y, Wang S, Borca-Tasciuc DA, Worobo RW, Moraru CI. Bacterial attachment and biofilm formation on surfaces are reduced by small-diameter nanoscale pores: how small is small enough? Nat Publ Gr 2015;1 [no. 15022].

[87] Veeh RH, Shirtliff ME, Petik JR, Flood JA, Davis CC, Seymour JL, et al. Detection of Staphylococcus aureus biofilm on tampons and menses components. J Infect Dis 2003;188(4):519-30. 
[88] Smith CB, Noble V, Bensch R, Ahlin PA, Jacobson JA, Latham RH. Bacterial flora of the vagina during the menstrual cycle: findings in users of tampons, napkins and sea sponges. Ann Intern Med Jun. 1982;96(6 Pt 2):948-51.

[89] Pruthi V, Al-Janabi A, Pereira BMJ. Characterization of biofilm formed on intra-uterine devices. Ind J Med Microbiol Jan. 2003;21(3):161-5.

[90] Tsanadis G, Kalantaridou SN, Kaponis A, Paraskevaidis E, Zikopoulos K, Gesouli E, et al. Bacteriological cultures of removed intrauterine devices and pelvic inflammatory disease. Contraception May 2002;65(5):339-42.

[91] Kavitha S, Natarajaseenivasan K, Shanmughapriya Santhanam, Francis Arumugam Lency. In vitro actinomycete biofilm development and inhibition by the polyene antibiotic, nystatin, on IUD copper surfaces. Biofouling 2012;28(9):929-35.

[92] Carrillo M, Valdez B, Vargas L, Alvarez L, Schorr M, Zlatev R, et al. In vitro Actinomyces israelii biofilm development on IUD copper surfaces. Contraception Mar. 2010;81(3):261-4.
[93] Elsayed S, George A, Zhang K. Intra-uterine contraceptive deviceassociated pelvic actinomycosis caused by Actinomyces urogenitalis. Anaerobe Apr. 2006;12(2):67-70.

[94] Pál Z, Urbán E, Dósa E, Pál A, Nagy E. Biofilm formation on intrauterine devices in relation to duration of use. J Med Microbiol Dec. 2005;54(12):1199-203.

[95] Miller L, MacFarlane SA, Materi HL. A scanning electron microscopic study of the contraceptive vaginal ring. Contraception 2005;71(1):65-7.

[96] Rabe L, Meyn L, Chen BA, Panther L, Hoesley C, Hillier SL. Effects of a vaginal ring containing maraviroc and or dapivirine worn for 28 days on the vaginal microflora. AIDS Res Hum Retroviruses Oct. 2014;30(S1). A290-A290.

[97] L. Hardy, V. Jespers, I. De Baetselier, J. Buyze, L. Mwambarangwe, V. Musengamana et al. Association of vaginal dysbiosis and biofilm with contraceptive vaginal ring biomass in African women, 2017 [in press].

[98] Hardy L, Abdellati S, Crucitti T. Biofilm formation by clinical isolates of Neisseria gonorrhoeae. Eurobiofilms 2013. 